\title{
Persisting primitive reflexes in medication-naïve girls with attention-deficit and hyperactivity disorder
}

\author{
Jana Konicarova' \\ Petr Bob ${ }^{1,2}$ \\ Jiri Raboch' \\ 'Center for Neuropsychiatric \\ Research of Traumatic Stress, \\ Department of Psychiatry, First \\ Faculty of Medicine, Charles \\ University, Prague, Czech Republic; \\ ${ }^{2}$ Central European Institute of \\ Technology, Faculty of Medicine, \\ Masaryk University, Brno, \\ Czech Republic
}

This article was published in the following Dove Press journal:

Neuropsychiatric Disease and Treatment

19 September 2013

Number of times this article has been viewed

Background and objectives: Recent and historical findings suggest that later-developed functions during brain ontogenesis related to higher levels of cognitive and motor integration tend to replace the older, more primitive, ones, and the persistence of the older functions may be linked to specific neuropsychiatric disorders. Currently, there is growing evidence to suggest that persisting primitive reflexes may be related to developmental and neurodegenerative disorders. Preliminary data also suggest that persisting primitive reflexes may be specifically linked to attention-deficit and hyperactivity disorder (ADHD).

Methods: In the study reported here, we tested to what extent the persisting primitive asymmetric tonic neck reflex and symmetric tonic neck reflex are related to ADHD symptoms measured by Conners' Parent Questionnaire in 35 medication-naïve girls of school age (8-11 years) with ADHD. The results were compared with those of a control group of 30 girls of the same age.

Results: This study showed that persisting primitive reflexes are closely linked to ADHD symptoms.

Conclusion: The data suggest that ADHD symptoms may be linked to more primitive neural mechanisms interfering with higher brain functions due to insufficiently developed cognitive and motor integration.

Keywords: ADHD, asymmetric tonic neck reflex, symmetric tonic neck reflex, developmental disorders

\section{Introduction}

Specific developmental disturbances due to various insults, brain damage, toxic influences, or psychological stress may determine higher levels of neurocognitive integration dysfunction that typically occur in children with attention-deficit and hyperactivity disorder (ADHD). ${ }^{1-3}$ One of the most important postnatal developmental deficits - which may have various etiological causes - influencing higher motor and cognitive functions is the persistence of several "primitive reflexes" that occurs in some neuropsychiatric disorders, such as the symmetric tonic neck reflex (STNR) and asymmetric tonic neck reflex (ATNR). ${ }^{4-6}$ These findings are in agreement with basic neurological concepts discovered by Hughlings Jackson, who proposed that certain functions developed later during the ontogenesis of the central nervous system (CNS) tend to replace older ones. ${ }^{7}$ Although Hughlings Jackson mainly focused on epilepsy in his works, he later discovered certain basic developmental rules describing CNS development that were characterized by hierarchical ontogenetic stages. ${ }^{8}$ When the higher stages of CNS development are not successfully achieved or are damaged,
Correspondence: Petr Bob Department of Psychiatry, Charles University, First Faculty of Medicine, Ke Karlovu II, 12800 Prague, Czech Republic Email petrbob@netscape.net 
lower neural functions may be disinhibited and their release from control may lead to the dysregulation of later-developed adaptive functions. ${ }^{7}$ In principle, these findings agree with data indicating hypofrontality in ADHD, ${ }^{9,10}$ which suggests that attentional and executive dysfunctions related to reduced activation in the right inferior frontal cortex, anterior cingulate cortex, supplementary motor area, and other regions are linked to inhibitory deficits. ${ }^{3}$

According to current findings and the best of our knowledge, there are few reported findings of persisting reflexes in dyslexia ${ }^{11,12}$ and preliminary findings suggesting that ADHD symptoms could be related to persistence of the primitive reflexes in later developmental stages than is usual. ${ }^{12,13}$ These studies suggest that further detailed research examining developmental conditions in ADHD is warranted and that such research might have significant consequences for understanding ADHD, dyslexia, and other neurodevelopmental disorders. ${ }^{11-13}$ Most recent studies examining atypical development in ADHD have predominantly studied boys, while studies of girls are very rare. However, the studies examining developing children have shown specific patterns mainly characterized by the girls' earlier brain maturation compared with that of boys. ${ }^{14}$ At this time, as far as we are aware, there is no reported study that has assessed whether ADHD symptoms are related to persistence of the primitive reflexes in medication-naïve children with a focus on sex-specific assessment. As such, in the study reported here we examined the extent to which the persistence of the primitive ATNR and STNR is related to ADHD symptoms in 35 medication-naïve girls of school age (8-11 years).

\section{Methods}

\section{Participants}

Data on 35 girls (mean age 9.51, standard deviation [SD] $=1.01$, age range 8-11 years) with ADHD diagnosed according to Diagnostic and Statistical Manual of Mental Disorders: Fourth Edition (DSM-IV) criteria characterizing their primitive reflexes and psychometric measures of ADHD symptoms were collected. All the patients were medication naïve and their assessment was done before starting any treatment. The ADHD diagnosis was combined hyperactive-inattentive subtype with occurrence of ADHD-based learning difficulties and, in a few cases, episodic enuresis. Exclusion criteria were other child psychiatric and neurological disorders, including conduct disorder, alcohol or drug dependency, substance abuse, and/or previous exposure to stimulant medication. Recruitment was based on consecutive visits of the untreated patients to the clinic, and the control group was recruited using school advertisements. The control group of 30 girls without ADHD (mean age $9.83, \mathrm{SD}=0.98$, age range $8-11$ years) fulfilled the same exclusion criteria.

Parents of all the participants gave written informed consent and the research was approved by the Charles University First Faculty of Medicine Ethical Committee within the framework of collaboration with the ELSPAC project, the project of the Center for Neuropsychiatric Research of Traumatic Stress, and the MSM0021620849 project at Charles University.

\section{Measurement of primitive reflexes}

The measurement of primitive reflexes was done twice by two independent examiners and the results of the two measurements averaged.

\section{ATNR}

We measured ATNR using the Schilder test. ${ }^{15}$ ATNR presents as the tonic reflex response that occurs in newborns; it normally vanishes at around 3 months of age. In the Schilder test, the subject stands with their feet together and the arms held straight out at shoulder level and height but with the hands relaxed at the wrists. In the test, the tester stands behind the subject and gives the instruction: "When I turn your head, I want you keep your arms straight out in front of you, as they are now. This means your arms remain in the same position, and only your head moves." Then the tester slowly rotates the subject's head until the chin is parallel with the shoulder, pauses for 10 seconds, then returns the head to the midline and again pauses for 10 seconds. The procedure is then done again with the head rotated to the other side. The activity is repeated up to four times.

Typical indicators of the ATNR include movement of the extended arms in the same direction as the head turn, dropping of the arms, or swaying and loss of balance. It was scored as follows: $0=$ no response (the arms remained straight out in front); 1 = slight movement of the arms up to $20^{\circ}$ to the same side as the head is turned or slight dropping of the arms; $2=$ movement of the arms up to $45^{\circ}$ as the head is turned or marked dropping of the arms; $3=$ arm movement greater than $45^{\circ}$ either to the side or down, swaying or loss of balance may occur.

\section{STNR}

STNR was measured by the Bender-Purdue Reflex Test. ${ }^{16}$ This reflex emerges at 6-8 months of life and is inhibited at between 9 and 11 months. In the Bender-Purdue test, the 
Table I Spearman correlations of primitive reflexes and attention-deficit and hyperactivity disorder (ADHD) symptoms (Conners' Parent Questionnaire [CPQ] and its subscales ${ }^{17}$ ) in 35 girls with ADHD

\begin{tabular}{lll}
\hline & ATNR & STNR \\
\hline CPQ & $0.643^{*}$ & $0.4 I I^{*}$ \\
I Conduct problems & 0.263 & 0.235 \\
II Anxiety & $0.39 I^{*}$ & 0.095 \\
III Impulsivity-hyperactivity & $0.473^{*}$ & $0.402^{*}$ \\
IV Learning problems & 0.306 & $0.469^{*}$ \\
V Psychosomatic & 0.07 I & 0.008 \\
VI Perfectionism & $0.44 I^{*}$ & 0.269 \\
VII Antisocial behavior & 0.163 & 0.003 \\
VIII Muscular tension & 0.258 & 0.073
\end{tabular}

Note: *Significant correlation coefficients at $P<0.05$; correlation coefficients higher than 0.45 are significant at $P<0.01$.

Abbreviations: ATNR, asymmetric tonic neck reflex; STNR, symmetric tonic neck reflex.

subject is instructed to maintain four point kneeling "table" position and to slowly move the head to look down as between the thighs. The position is held for up to 5 seconds and then the head is slowly moved upward as if looking at the ceiling. This procedure is repeated up to six times.

Typical indicators of the reflex are any bending of the arms due to head flexion and/or raising of the feet, straightening of the arms and flexion of the knees as a result of head extension, any bending of the arms due to head flexion and/or raising of the feet, and straightening of the arms and flexion of the knees due to head extension. The test was scored as follows: $0=$ no response; $1=$ tremor in one or both arms or slight hip movement; $2=$ movement of the elbow on either side and/or definite, movement in the hips, or arching of the back; 3 = bending of the arms on head flexion or movement of the bottom back on head extension; $4=$ bending of the arms to the floor, or movement of the

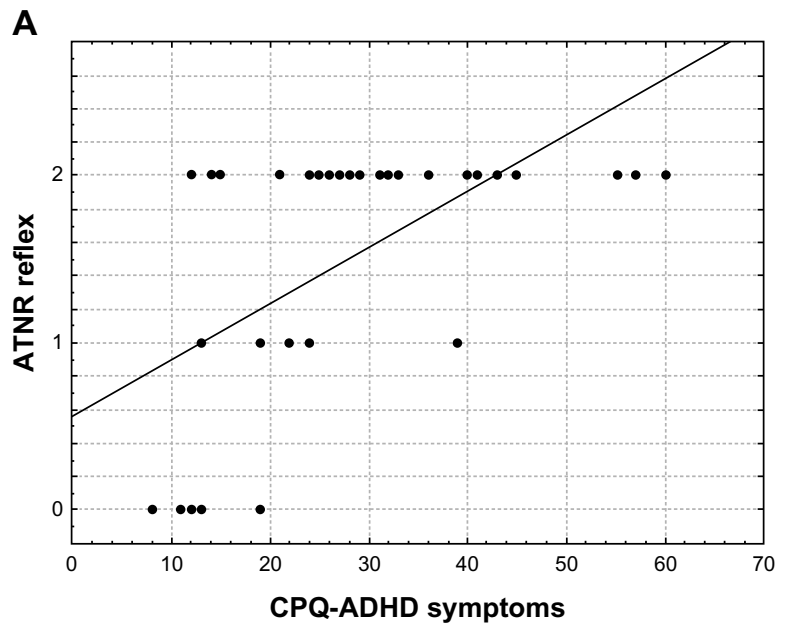

bottom back onto the ankles, so that the subject is sitting in the cat position.

\section{Psychometric measure of ADHD symptoms}

A frequently used measure of ADHD symptoms is the Conners' Parent Questionnaire (CPQ).${ }^{17}$ The CPQ is 93 -item scale of symptoms that are most commonly associated with behavioral disorders and related to children and adolescents (aged 3-17 years), and can measure treatment changes and outcome assessment purposes.

The questionnaire enables a total score to be calculated as well as scores for subscales based on the factor structure of the questionnaire: I Conduct problems (items 39, 40, 41, 47, 48, 51, and 69); II Anxiety (items 8-11, 42, 43, and 64); III Impulsivity-hyperactivity (items 78, 80-84, 89, and 90); IV Learning problems (items 45, 62, 63, 67); V Psychosomatic difficulties (items 6 and 21-24); VI Perfectionism (items 3 and 76-78); VII Antisocial behavior (items 71-73 and 75); and VIII Muscular tension (items 12-14 and 36). The symptoms are rated on a four-point Likert scale (from 0 to 3 ) by either one or both parents of the child.

\section{Statistical analysis}

For statistical evaluation of scores of the measures of ATNR, STNR, and ADHD symptoms, Spearman correlation coefficients were determined and multiple linear regression analysis was undertaken. Nonparametric analyses were preferred because CPQ, ATNR, and STNR data do not have normal distribution. All the methods of statistical evaluation were performed using the software package STATISTICA (v 6; StatSoft Inc, Tulsa, OK, USA).

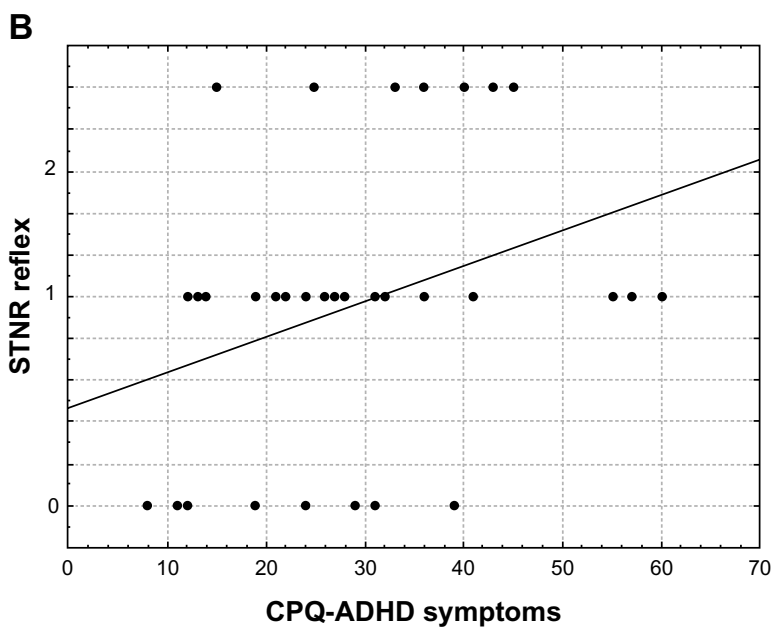

Figure I Dependency graphs of the primitive asymmetric tonic neck reflex (ATNR) (A) and symmetric tonic neck reflex (STNR) (B) with attention-deficit and hyperactivity disorder (ADHD) symptoms (Conners' Parent Questionnaire [CPQ] ${ }^{17}$ ) in 35 girls with ADHD. 


\section{Results}

ADHD symptoms measured by total score of the CPQ and its subscales were significantly correlated with ATNR and STNR scores; that is: CPQ and ATNR, $R=0.64$; CPQ and STNR, $R=0.41$; II Anxiety and ATNR, $R=0.39$; III Impulsivity-hyperactivity and ATNR, $R=0.47$; III Impulsivity-hyperactivity and STNR, $R=0.40$; IV Learning problems and STNR, $R=0.47$; and VI Perfectionism and ATNR, $R=0.44$ (Table1, Figure1). Other correlations were not statistically significant. Spearman rank correlation coefficients with $R$ higher than 0.43 were significant at $P<0.01$, with Fisher's $z>0.46$, and Spearman rank correlation coefficients with $R>0.33$ significant at $P<0.05$, with Fisher's $z>0.35$. These correlations indicate that significant manifestations of ADHD symptoms are associated with persisting ATNR and STNR responses. We compared CPQ, ATNR, and STNR scores for the 35 study subjects with those for the 30 control participants. The control group had no ADHD symptoms, and none of this group manifested ATNR (the score was zero in all cases), while only one case of STNR response was found, with a score of 1 .

To analyze effects of ATNR and STNR on CPQ, we used a multiple linear regression to determine whether persisting primitive reflexes in their specific interactions are proportionally linked to increased levels of CPQ. Multiple $R=0.60$ was found to be statistically significant $(P=0.0008 ; \mathrm{F}=8.99$; sequential consistency $(\mathrm{SC})$ model $=2,375$; $\mathrm{SC}$ residuals $($ resid $)=4,229$; processor consistency $(\mathrm{PC})$ model $=1187$; PC resid $=132$ ) which enables CPQ to be defined as a linear function of two variables: $\mathrm{CPQ}=\mathrm{F}(\mathrm{ATNR}, \mathrm{STNR})$.

\section{Discussion}

Recent findings show that a high proportion of children with ADHD exhibit motor abnormalities. ${ }^{3,4}$ According to brain imaging studies, these abnormalities are probably linked to prefrontal cortex deficits that influences attention and executive functions. ${ }^{18-20}$ The abnormalities may also be of cerebellar origin and ADHD children in many cases exhibit atrophy in cerebellar regions associated with motor dysfunctions that are most likely linked to inhibitory deficits. ${ }^{3,21,22}$ Disinhibitory processes related to disturbed motor functions are probably also linked to persisting primitive reflexes that were not sufficiently suppressed in later stages of development. According to some evidence, persisting primitive reflexes may occur in various neuropsychiatric syndromes such as schizophrenia or various forms of dementia ${ }^{5,6,20,23}$ and have also been observed in patients with dyslexia $^{11,24}$ and in school-aged children with ADHD. ${ }^{12,13,25,26}$
In our previous study on medicated ADHD children, ${ }^{13}$ we found that boys had higher levels of ADHD symptoms and that there was little statistically significant difference in persisting primitive ATNR between girls and boys. Moreover, studies that have focused on persistent ATNR in dyslexia ${ }^{11,24}$ have not reported differences between girls and boys. In this context, this study represents an important step focused on detailed analysis of ADHD children in medication naïve conditions. The results show that persistent ATNR and other primitive reflexes that may occur in later age specifically influence ADHD symptoms related to hyperactivity due to muscular tension, which also may have specific influence on attentional functions.

Taken together recent research predominantly does not take into account differences between ADHD girls and boys. ${ }^{27,28}$ Nevertheless several comparisons showed few sex effects in core clinical manifestations of ADHD. In addition, girls compared with boys, have significantly more parentrated emotional symptoms and more likely they become victims of bullying. Girls and boys have similar levels of coexisting psychiatric and physical health problems, and receive the same types of treatment although fewer girls than boys are referred for ADHD treatment. ${ }^{27,28}$ Therefore, research focused on girls with ADHD seems to be particularly important and, in the future, detailed comparison of girls and boys may provide particularly important findings and have significant therapeutic implications.

The results of this study support the hypothesis that ADHD symptoms are linked to the persisting primitive ATNR and STNR in girls. Further data are needed to find specific sex differences and to determine the relationships between ADHD symptoms and various primitive reflexes that are possible to assess in school-aged children. Together, our data suggest a hypothesis for future research that ADHD symptoms may present a process related to primitive neural mechanisms, such as primitive reflexes, interfering with higher-level brain functions due to insufficiently developed cognitive and motor integration. In this context, Hughlings Jackson's concept may in principle be useful to explain and understand certain developmental changes as a consequence of disturbances between higher and lower levels of cognitive and motor functions during brain processing that might cause processes related to "dissolution" (or disintegration) of mental functions. ${ }^{8,12}$

\section{Conclusion}

The preliminary data reported here show that detailed analysis of persisting primitive reflexes in children with develop- 
mental disorders and comparisons of differences between girls and boys with ADHD and dyslexia may offer important new findings with specific consequences for treatment. As such, further research in this area is warranted.

\section{Acknowledgments}

The study was supported by the Charles University grant PRVOUK, project MSM0021620849 provided by the Czech Ministry of Education, and the Central European Institute of Technology (CZ.1.05/1.1.00/02.0068) project of the European Regional Development Fund.

\section{Disclosure}

The authors declare no conflicts of interest in this work.

\section{References}

1. Teicher MH, Tomoda A, Andersen SL. Neurobiological consequences of early stress and childhood maltreatment: are results from human and animal studies comparable? Ann N Y Acad Sci. 2006;1071: 313-323.

2. Kolb B, Gibb R. Brain plasticity and behaviour in the developing brain. J Can Acad Child Adolesc Psychiatry. 2011;20(4):265-276.

3. Hart H, Radua J, Nakao T, Mataix-Cols D, Rubia K. Meta-analysis of functional magnetic resonance imaging studies of inhibition and attention in attention-deficit/hyperactivity disorder: exploring task-specific, stimulant medication, and age effects. JAMA Psychiatry. 2013;70(2): 185-198.

4. Zafeiriou DI. Primitive reflexes and postural reactions in the neurodevelopmental examination. Pediatr Neurol. 2004;31(1):1-8.

5. Youssef HA, Waddington JL. Primitive (developmental) reflexes and diffuse cerebral dysfunction in schizophrenia and bipolar affective disorder: overrepresentation in patients with tardive dyskinesia. Biol Psychiatry. 1988;23(8):791-796.

6. Sanders RD, Gillig PM. Reflexes in psychiatry. Innov Clin Neurosci. 2011;8(4):24-29.

7. Franz EA, Gillett G. John Hughlings Jackson's evolutionary neurology: a unifying framework for cognitive neuroscience. Brain. 2011;134(Pt 10):3114-3120.

8. Jacyna LS. Process and progress: John Hughlings Jackson's philosophy of science. Brain. 2011;134(Pt 10):3121-3126.

9. Rubia K, Overmeyer S, Taylor E, et al. Hypofrontality in attention deficit hyperactivity disorder during higher-order motor control: a study with functional MRI. Am J Psychiatry. 1999;156(6):891-896.

10. Zang YF, Jin Z, Weng XC, et al. Functional MRI in attention-deficit hyperactivity disorder: evidence for hypofrontality. Brain Dev. 2005;27(8):544-550.
11. McPhillips M, Hepper PG, Mulhern G. Effects of replicating primary-reflex movements on specific reading difficulties in children: a randomised, double-blind, controlled trial. Lancet. 2000;355(9203): $537-541$.

12. Konicarova J, Bob P. Principle of dissolution and primitive reflexes in ADHD. Act Nerv Super (Praha). 2013;55(1-2):135-138.

13. Konicarova J, Bob P. Asymmetric tonic neck reflex and symptoms of attention deficit and hyperactivity disorder in children. Int J Neurosci. Epub June 5, 2013.

14. Mahone EM, Wodka EL. The neurobiological profile of girls with ADHD. Dev Disabil Res Rev. 2008;14(4):276-284.

15. Morrison DC. Neurobehavioral and Perceptual Dysfunction in Learning Disabled Children. Lewiston, NY: CJ Hogrefe; 1985.

16. Bender ML. The Bender-Purdue Reflex Test and Training Manual. San Rafael, CA: Academic Therapy; 1976.

17. Conners CK. Parent symptom questionnaire. Psychopharmacology Bulletin 21. 1985;21(4):816-822.

18. Arnsten AF. Toward a new understanding of attention-deficit hyperactivity disorder pathophysiology: an important role for prefrontal cortex dysfunction. CNS Drugs. 2009;23 Suppl 1:33-41.

19. Shaw P, Rabin C. New insights into attention-deficit/hyperactivity disorder using structural neuroimaging. Curr Psychiatry Rep. 2009;11(5):393-398.

20. Makris N, Biederman J, Monuteaux MC, Seidman LJ. Towards conceptualizing a neural systems-based anatomy of attention-deficit/ hyperactivity disorder. Dev Neurosci. 2009;31(1-2):36-49.

21. Baillieux H, De Smet HJ, Paquier PF, De Deyn PP, Mariën P. Cerebellar neurocognition: insights into the bottom of the brain. Clin Neurol Neurosurg. 2008;110(8):763-773.

22. O'Halloran CJ, Kinsella GJ, Storey E. The cerebellum and neuropsychological functioning: a critical review. J Clin Exp Neuropsychol. 2012;34(1):35-56.

23. Links KA, Merims D, Binns MA, Freedman M, Chow TW. Prevalence of primitive reflexes and Parkinsonian signs in dementia. Can J Neurol Sci. 2010;37(5):601-607.

24. McPhillips M, Jordan-Black JA. Primary reflex persistence in children with reading difficulties (dyslexia): a cross-sectional study. Neuropsychologia. 2007;45(4):748-754.

25. Konicarova J, Bob P. Retained primitive reflexes and ADHD in children. Act Nerv Super (Praha). 2012;54(3-4):135-138.

26. Taylor M, Houghton S, Chapman E. Primitive reflexes and attentiondeficit/hyperactivity disorder: Developmental origins of classroom dysfunction. Int J Spec Educ. 2004;9(1):23-37.

27. Ford T, Goodman R, Meltzer H. The British Child and Adolescent Mental Health Survey 1999: the prevalence of DSM-IV disorders. JAm Acad Child Adolesc Psychiatry. 2003;42(10):1203-1211.

28. Nøvik TS, Hervas A, Ralston SJ, Dalsgaard S, Rodrigues Pereira R, Lorenzo MJ; ADORE Study Group. Influence of gender on attentiondeficit/hyperactivity disorder in Europe - ADORE. Eur Child Adolesc Psychiatry. 2006;15 Suppl 1:15-24.
Neuropsychiatric Disease and Treatment

\section{Publish your work in this journal}

Neuropsychiatric Disease and Treatment is an international, peerreviewed journal of clinical therapeutics and pharmacology focusing on concise rapid reporting of clinical or pre-clinical studies on a range of neuropsychiatric and neurological disorders. This journal is indexed on PubMed Central, the 'PsycINFO' database and CAS.

\section{Dovepress}

The manuscript management system is completely online and includes a very quick and fair peer-review system, which is all easy to use. Visit http://www.dovepress.com/testimonials.php to read real quotes from published authors. 